\title{
Value-Risk Analysis of Crowdsourcing in Pakistan's Perspective
}

\author{
Muhammad Saady, Qurat-ul-Ain, Sidra Anwar, Sadia Anayat, Samia Rafique \\ Virtual University, Pakistan, COMSATS Institute of Information Technology, Islamabad, Pakistan, Memorial \\ University of Newfoundland, St. Johns, Canada, Govt. College Women University, Sialkot, Pakistan, Govt. College \\ Women University, Sialkot, Pakistan \\ Email: saady_chohan@yahoo.com, q.ainne45@gmail.com, engrsid.es@gmail.com, cssadiaanayat@gmail.com, \\ samia.rafique@gcwus.edu.pk
}

Received: 25 December 2020; Accepted: 26 January 2021; Published: 08 April 2021

\begin{abstract}
The benefits of crowdsourcing are enabled by open environments where multiple external stakeholders contribute to a firm's outcomes. In recent years, crowdsourcing has emerged as a distributed model of problem-solving and market development. Here, model assignments are assigned to networked individuals to complete so that the manufacturing expense of a business can be minimized considerably. The main objective of this research is to develop a methodology which will capture the value generation process in the presence of uncertainties (Risk factors) in crowdsourcing context. This study is designed to make an important contribution to the field of practice and knowledge. Value-Risk Analysis of crowd souring is one of the under studies Worldwide, especially in Pakistan. Provided the need, we have discussed the crowdsourcing as business process and presented an understanding of the risks associated with crowdsourcing use and possible strategies that can be used to maximize the value and minimize the identified risks.

For the better understanding of crowdsourcing practices in Pakistan, three case studies were conducted based on three well reputed organizations of Pakistan and results gathered to help understand its practices, some of the risks associated with it and how they manage those risks.
\end{abstract}

Index Terms: Crowdsourcing, Risk Management, Value Generation, Technological Advancements, Digital Product Designs

\section{Introduction}

In recent years, crowdsourcing has emerged as a distributed model of problem-solving and market development. In the crowdsourcing model assignments are assigned to networked individuals to complete so that the manufacturing expense of a business can be minimized considerably. Howe (2006) at first utilized the expression "crowdsourcing" in the June 2006 issue of Wired magazine: "Technological advances in everything from product design software to digital video cameras are breaking down the cost barriers that once separated amateurs from professionals. Hobbyists, parttimers, and dabblers suddenly have a market for their efforts, as smart companies in industries as disparate as pharmaceuticals and television discover ways to tap the latent talent of the crowd. The labor isn't always free, but it costs a lot less than paying traditional employees. It's crowdsourcing." Much work has since focused on various aspects of crowdsourcing, such as statistical methods and performance analysis. The advancement of data and correspondence innovation (ICT), joined with the development of informal communities and web, has changed plan of action lately (Buhalis and O'Connor 2005, Garrigos 2010). In present field, both firms and clients need to take an interest out and out in every one of the procedures of business improvement. To see new business condition, the significance of group is basic (Garrigos et al. 2011). Crowdsourcing is moderately another wonder. It is associated with both the development of the web and the all- inclusiveness of cell phones and in addition with innovative headways (Howe 2006). As crowdsourcing enables organizations to work with innumerable individuals in a direct and practical way (Howe 2009, Kohler 2015). Oxford University has utilized a crowdsourcing way to deal with its Galaxy Zoo extend (Eaton 2009). In that approach, people in general were permitted to give criticism and contribution to a venture to delineate world.

Subsequently, college finished the assignment in four months instead of two years which it would have taken if depending on inner staff and accessible assets. Individuals around the globe in crowdsourced undertakings can impart and team up for work whenever. Changes or proposals could be set aside a few minutes and new thoughts. Overall strength of a crowdsourced project results from the heterogeneity and diversity of its participants and users. This variety of interests leads to the generalization of the results, continuous support for the project and the development of pathways that will be useful. 


\subsection{Early Practice of Crowdsourcing}

Examples are drawn from several sources such as knowledge-based projects like the Galaxy Zoo initiative, and commercial activities that took place with clothing businesses, like Threadless. Galaxy Zoo was launched in 2007 with a simple objective. Users were asked to review, survey and organize data. The data was collection of approx.one million images that were taken by a robotic telescope (Source: GalaxyZoon.org). Users were asked to take a small section and then review the images. They observed for galaxies in those images and assigned them to one of two groups: elliptical or spiral. The response to the project was great and keen volunteers from all over the world were flocking to the site to assess data. Amazon is known as one of the innovators in the field of crowdsourced user feedback and commendation. While the company transformed the face of marketing, both on and offline, it has made an important contribution to the practice of crowdsourcing. Amazon's online reviews and feedbacks have become a vital source of information to innumerable users. Nothing describes a product's failings quicker than several poor reviews on Amazon.

Howe (2009) identifies, in his book-length examination of crowdsourcing, an early example of the process sin a Tshirt company Threadless (www.threadless.com 2012), which was established by two friends. Their business plan was quite simple: they liked to wear cool and nice T-shirts, and they had an idea that there was a market for them. The challenge was to design cloth and then promote them. The Internet made this possible for them. They invited designers to post their designs on the website, and users were invited to vote on those designs. The voters were drawn from the web community. Designers would invite their friends and supporters to vote for their products and the audience continued to grow exponentially and as a result, reputation of the company grew. Customers liked what they found on the Threadless site and recommended their friends. People enjoyed this collaborative process. Howe (2009) believes that Threadless really isn't in the T-shirt business but what it sells is community. Using the basic principles of crowdsourcing, Threadless was able to find its target audience and sell to the audience successfully while turning a steady revenue.

Above disused examples are earlier uses of crowedsourcing, as crowedsoursing is still a new phenomenon. Social media have evolved in many respects alongside crowdsourcing as a source of providing a context and format for the generated content. Sites like Twitter (twitter.com) and Facebook (facebook.com) provide users with the opportunity to share their views and opinions and articulate themselves on the problems that are important to them.

\subsection{Limitations of Crowdsourcing}

Crowdsourcing involves a mass of ethical concerns. The reliability and validity of a document is derived from its authorship; therefore, an identifiable author provides proof of authenticity and originality of a specific document. Moreover, the formation of a document is comparable to plagiarism if it is formed with help of multiple unaccredited sources. In fact, some might propose that crowdsourcing devalues the involvement of the individual and makes it difficult to support traditional research. Furthermore, the cost-effectiveness of crowdsourcing devalues both the work of professionals and other researchers and Intellectual Property (IP), which becomes subject to abuse.

\subsection{Problem statement}

Innovation is less frequently undertaken in a closed and integrated, in-house way but has transformed more into an open call where many participants are involved in the different steps of the process. Crowdsourcing encourages companies in their effort to re-evaluate and re-design business processes and diversify a greater task to a heterogeneous group of people to achieve a common goal. In Pakistan's perspective, crowdsourcing is still unknown to many organizations and if there is any application of this phenomena then there still is a need of a methodology to capture the value creation process in the presence of uncertainty (risk factors) in the crowdsourcing context. So the main objectives of this research are to

- Develop a methodology which will capture the value generation process in presence of uncertainties (Risk factors) in crowdsourcing context.

- View crowdsourcing as business process and provide an understanding of the risks associated with crowdsourcing use and possible strategies that can be used to maximize the value and minimize the identified risks.

We have studied the crowdsourcing as business process and provide an understanding of the risks associated with crowdsourcing use and possible strategies that can be used to maximize the value and minimize the identified risks. The accompanying subsections portray the progression in crowdsourcing by recognizing cases of both present and early practices. Crowdsourcing would not be conceivable without the Internet (Surowiecki 2004).

The Web 2.0 assumes a critical part in supporting this capacity. With a solitary snap of a mouse one can showcase millions or achieve a huge number of specialists. It highlights that web is basic to crowdsourcing. The business world has ended up being all inclusive aggressive. Advancement is less much of the time embraced in a shut and incorporated, and in-house way however has changed more into an open call where numerous members are included in the distinctive strides of the procedure. Crowdsourcing energizes organizations in their push to re-assess and re- outline business forms 
and differentiate a more prominent undertaking to a heterogeneous gathering of individuals to accomplish a shared objective. The act of crowdsourcing has turned into an important business apparatus in this day and age of business and innovation, for thought era, item improvement and investigating (Saxton et al. 2013). According to Howe (2006), there are four types of crowdsourcing strategies: the collective intelligence, crowd creation, voting, and crowd funding; Crowd Intelligence, Crowdfunding, Voting and Crowd creation.

This study is designed to make an important contribution to the field of practice and knowledge. Value-Risk Analysis of crowd souring is one of the undone studies in Pakistan and there is need to study such areas. While for the business, the crowdsourcing application is on its way to being widely used, acknowledged and valued but its relationship to value generation in presence of certain risk factors has been overlooked. This research Develop a methodology which will capture the value generation process in presence of uncertainties (Risk factors) in crowdsourcing context. We have studied the crowdsourcing as business process and provide an understanding of the risks associated with crowdsourcing use and possible strategies that can be used to maximize the value and minimize the identified risks.

\section{Literature Review}

\subsection{Background}

A few creators join crowdsourcing to an open source program in programming (Libert and Spector 2007; Bacon 2009; Howe 2009). In open source programs, a few people have admittance to configuration stage and can build up an item paying little respect to the requirements of conventional protected innovation law. This will bring about viable item that is created cooperatively and is uninhibitedly accessible to everybody (Levy 1984; Himanen 2001). Open source gifts everybody measure up to get to. In spite of the fact that its application is constrained to programming improvement as well as it is regularly alluded in this unique situation. Itaught to be utilized as a part of general item advancement setting. Cosmic system Zoo was propelled in 2007 with a basic goal. Clients made a request to audit, review and organize information. The information was gathered of approx. one million images that were taken by an automated telescope (Source: GalaxyZoon.org).

Clients were made a request to take a little area and after that survey the pictures. They watched for universes in those pictures and allocated them to one of two gatherings: circular or winding. Amazon is known as one of the innovators in the field of crowdsourced user feedback and commendation (Libert and Spector 2007). While the organization changed the substance of showcasing, both on and disconnected, it has made an imperative commitment to the act of crowdsourcing. Amazon's online surveys and criticisms have turned into an indispensable wellspring of data to endless clients. Casares- Giner et al. (2011) showed that the use of web 2.0 innovation and the ascent of portable comprehensiveness through current advanced cells have incredibly influenced display organization.

\subsection{Related Work}

The expression "crowdsourcing" was first utilized as a part of 2006 and it has been re-imagined and investigated by various scientists. The relentless development of the portable Internet and developing utilization of interpersonal interaction sites has increment the prevalence of crowdsourcing. The dynamic commitments by human people on the Internet has immensely expanded which have brought a few social developments: groups and people now cooperate in type of huge gatherings that share just intrigue the one identified with the issue they are as of now taking a shot at. Crowdsourcing is a standout amongst the most. Howe (2006) recommended fig. 1 in his initially Wired Magazine as a meaning of crowdsourcing, demonstrating how the characterized work of a person inside an association or a corporate group was appointed to an unclear and vast group of individuals in type of an open call. Later Howe altered his definition to clarify that the demonstration of crowdsourcing included some kind of installment or acknowledgment to make a refinement from built up associate generation, creative advancements being utilized by associations, EstellésArolas, and González-Ladrón-de-Guevara (2012) characterize it as a participative circulated online process that allows the member to play out an undertaking for the determination of an issue. Whitla (2009) characterizes the crowdsourcing as the 'firms outsource activities to an online web community or to crowd in the form of an open call. In crowdsourcing, any number of crowd can complete assigned task and can get paid for their effort'. However, crowdsourcing is still a new phenomenon; therefore, it is a still difficult to define this concept or its process.

\subsubsection{Evolution of crowdsourcing}

Jurvetson first instituted the expression "crowdsourcing" and a writer of Wired magazine, Howe advanced it in 2006 (Brabham 2013) and characterized it as "the demonstration of choosing an undertaking customarily performed by an assigned specialist or representative and outsource it to an unclear, for the most part vast gathering of individuals in a type of an open call" (Howe 2009). Today the constant Web and the universality of portable buyer gadgets invigorate the general improvement to a propelled organize. 


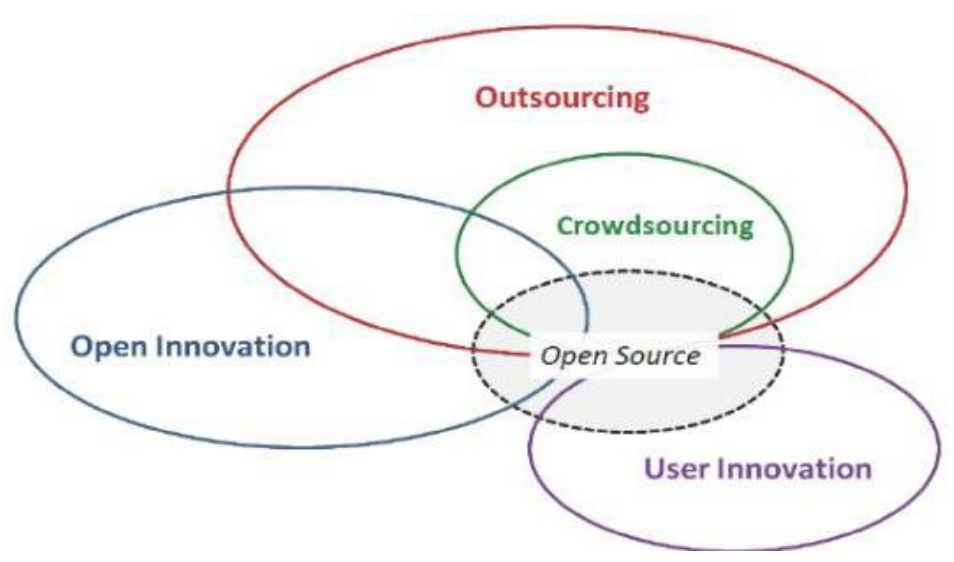

Fig.1.Conceptual intersections of crowdsourcing

\subsubsection{Approaches to crowdsourcing}

Schelske (2008) noticed that the idea of open advancement has both subjectively and quantitatively intensification in crowdsourcing. Crowdsourcing is directed to the group by an open call through the Internet as opposed to through diverted methodologies inside organizations (Schenk and Guittard 2009). Crowdsourcing shows three classes of colleagues with personal stakes:

- Providers (Individuals forming the crowd).

- Companies benefitting from the crowd.

- Links between crowds and client companies (mostly in form of specialized intermediaries).

These categories are due to the disruptiveness of the topic still under constant development; its meaning is not yet fully defined and has been distinguished with other open- innovation, user-innovation or open-source concepts (Schenk and Guittard 2009).

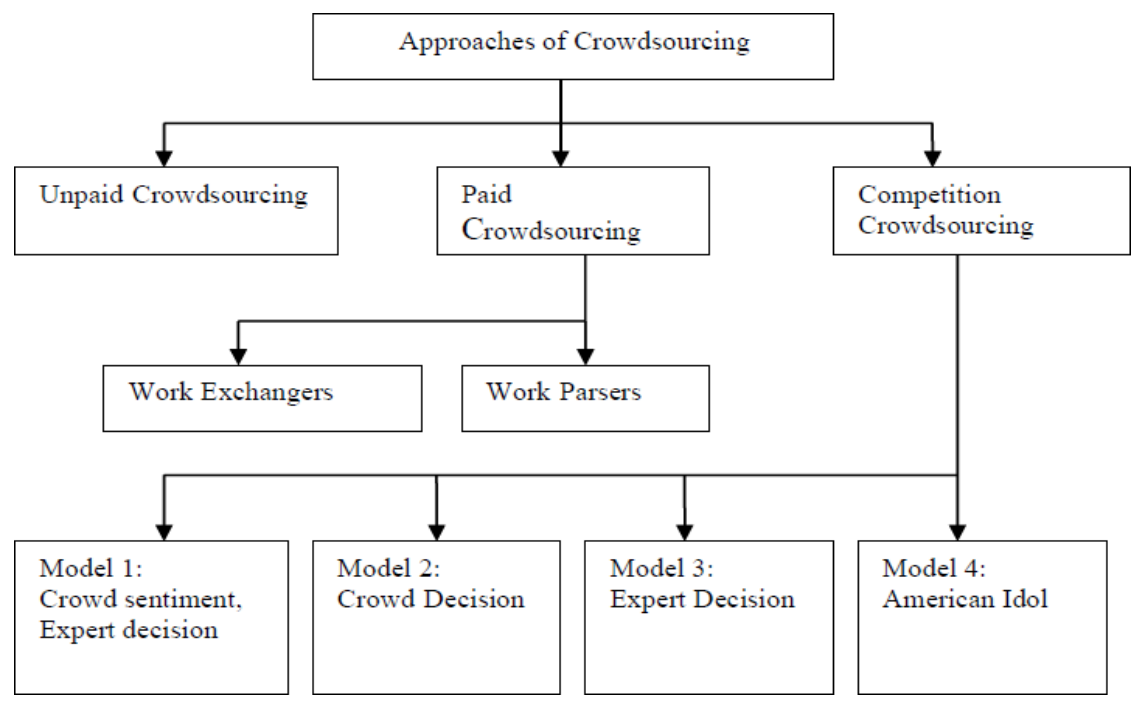

Fig.2. Approaches to crowdsourcing

\subsubsection{Risk associated with crowdsourcing}

The essential favorable position of crowdsourcing in safeguarding danger is its cheapness. In spite of the many advantages of crowdsourcing, a few risks have been recognized, albeit most crowdsource experts saw the advantages to exceed the dangers.

a) Turbulence risk

The hugeness of turbulence dangers relates to the unusualness and expanding intricacy of the business condition. These dangers are normally experienced by huge scale organizations because of unanticipated components (European Commission 2010). Turbulence risks may bring about: 
- Conceivable weakening or annihilation of the brand or venture.

- Individuals required in crowdsourcing forms begin having more impact on brands or tasks, different clients and the media.

- Disruptively affecting business both in a positive and negative way

b) Leakage of sensitive information

Security dangers associated with crowdsourcing are fundamentally engaged around the danger of releasing touchy data to people in general and even to contenders. To use crowdsourcing methodologies, firms of need to discharge some applicable data as crude material for the group to work with.

c) Quality Risk

Experts may be worried about conceivable quality dangers. Since the errand could be allotted to individuals, they don't have the foggiest idea about, the customers or requesters are presented to major issues in regards to the nature of results (Schulze et al. 2011).

\subsubsection{Effect of Project Risks on Performance of Crowdsourcing project}

Shan Liu et al. (2016) examined dangers measurements of crowdsourcing undertakings and researched the patterns in those measurements and execution crosswise over crowdsourcing ventures with low, medium and high hazard levels. Shan lui et al. (2016) shows that a few qualities of crowdsourcing undertaking like venture mode and sort likewise impact extend execution.

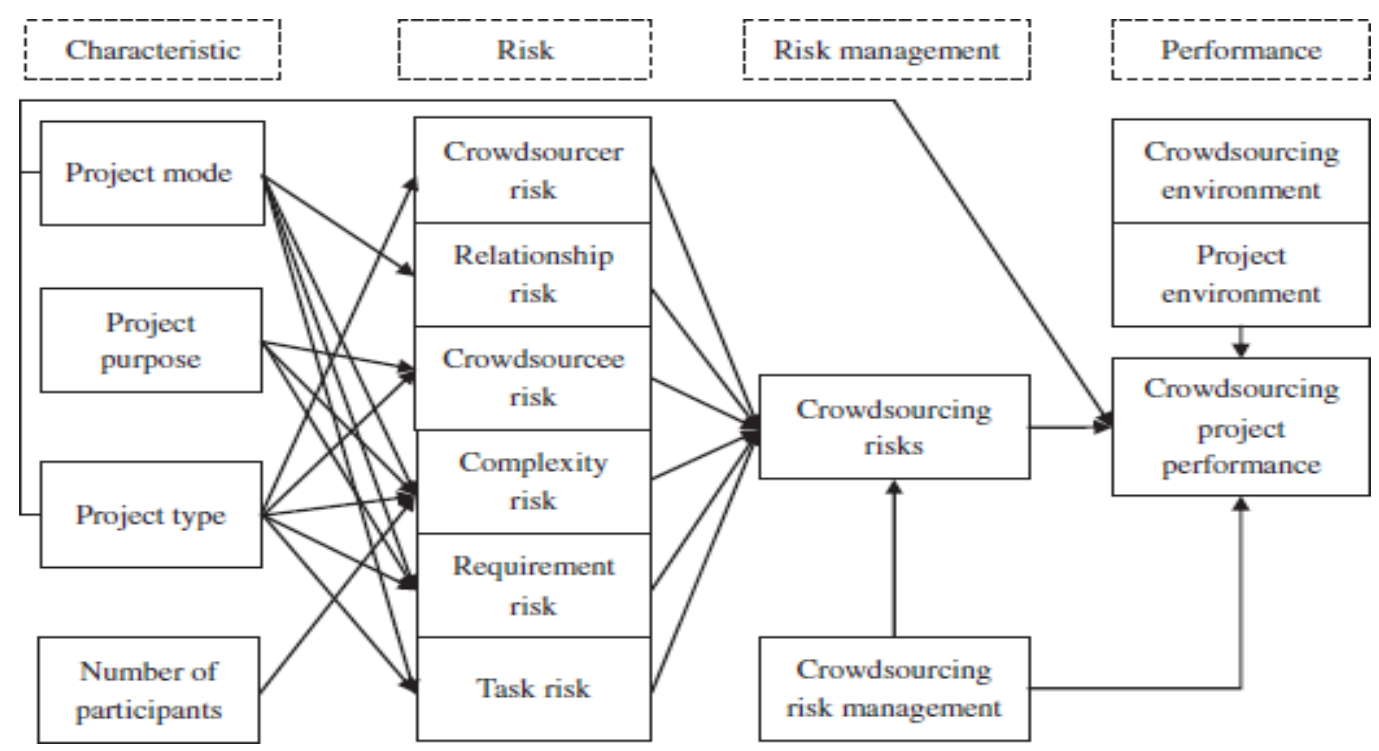

Fig.3. Model of Project characteristics, project risks and performance on crowdsourcing projects

As crowdsourcing undertakings are produced in crowdsourcing setting, both crowdsourcing and venture condition impact crowdsourcing venture execution. In this way, suitable practice for hazard administration is important to relieve dangers. Different crowdsourcing dangers are related contrarily with venture execution (Teller and Kock, 2013, Guo et al., 2014). Thus, Crowdsourcing venture execution can be improved and hazards levels of crowdsourcing can be decreased by powerful crowdsourcing hazard administration.

\section{Methodology}

Mixed method research, for the data collection industry experts and customers of leading crowdsourcing platforms will be interviewed and historical records of the systems will be observed and some cases will be drawn. Sample size for proposed work is Pakistani organizations Cases discusses crowdsourcing practice in presence of some risks in those organizations. Those cases will be then mapped on proposed model while dealing crowdsourcing in a business context. When dealing with crowdsourcing as a business process, it is a stage in which when objectives are realized they are exposed to certain risks. All the objectives of the process made up a value. In Research, case studies will be done and Risk and value will qualitatively be model in crowdsourcing context for those case studies. Calculated system for this review proposed in Figure addresses the crowdsourcing procedure and it indicates dangers administration related with the utilization of crowdsourcing identified with the crowdsourcing procedure, the group (suppliers/performing artists), the go-betweens and the searchers (organizations). The framework covers the study's objective to determine the level of 
risk involved, generate value of the process and integrate both risk and value to perform value-risk analysis.

\subsection{Crowdsourcing Process Model - Overview}

Howe (2006) offers the meaning of crowdsourcing as "Crowdsourcing speaks to the demonstration of an organization or foundation taking a capacity once performed by workers and outsourcing it to an indistinct (and by and large huge) system of individuals in type of a measurement in that the reaction time, scale and simplicity of reach to this workforce is equivalently bigger. Extend, extraordinary piece, business issue or particular need can be posted on the Web and it accordingly give a huge number of individuals access to chances to give and finish winning work. This free market approach guarantees the best item for the venture by developing solid rivalry and decision. A standout amongst the most conspicuous cases of focused crowdsourcing is the network show American Idol. Two principle wellsprings of inspiration drive the jam in focused crowdsourcing: an advanced reserve and the open door for individuals to test their ability or particular aptitudes. The achievement of a focused crowdsourcing effort is to a great extent relied on upon a very much arranged and executed correspondence technique to transport the subject about a particular challenge and reach to the welcomed swarm. Assessments by specialists and votes of the overall population decide the champ of the aggressive crowdsourcing challenge. For better understanding the scope of research Figure 4 presents a model of crowdsourcing process as follows ahead.

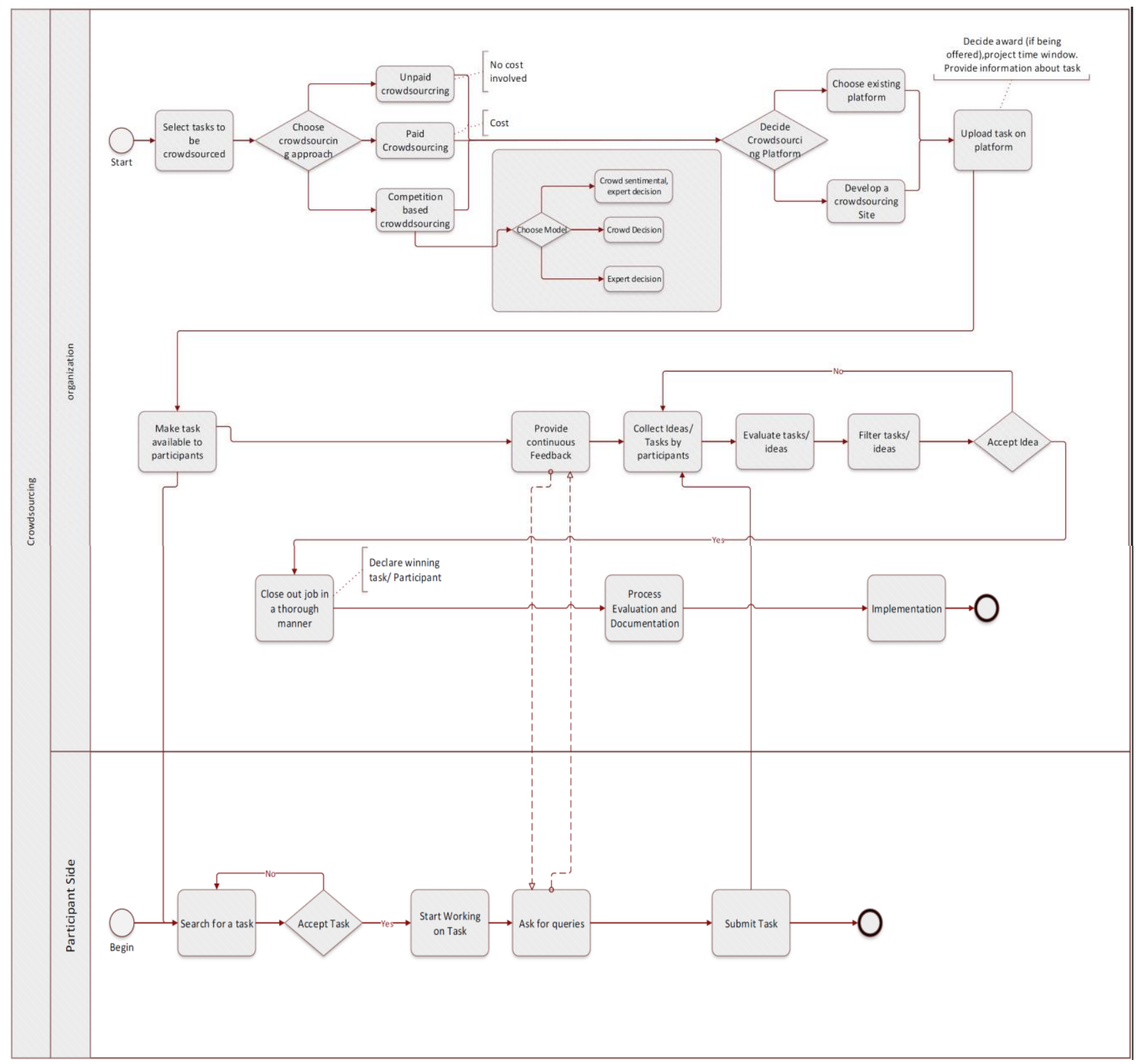

Fig. 4. Crowdsourcing Process Model 


\subsection{Process Model Description}

The initial phase of crowdsourcing process covers activities which should be identified before the actual start of the project. Objective of this task is to define a detail plan of all the activities which are going to be performed through crowdsourcing. Competitive crowdsourcing is a term that is still in its early stages but it is gaining acknowledgement in terms of corporate interest (Carpenter 2010). Competitive crowdsourcing has its own set of activities for gathering, filtering and selecting among submissions of contributors with altering motivations of certain incentives (Carpenter 2010). One of the most prominent examples of competitive crowdsourcing is the television show American Idol. Two main sources of motivation drive the crowd in competitive crowdsourcing: a promoted fund and the opportunity for members to test the ir talent or specific skills. The success of a competitive crowdsourcing campaign is largely depended on a well- planned and executed communication strategy to transport the theme about a specific contest and reach to the invited crowd.

In case of paid crowdsourcing, an appropriate bounty amount or award offering is essential. The boundaries of what is an effective bounty or reward to offer are very much in flux. Crowdsourcing as a concept is so new that specific tasks like designing a logo or writing 1000 words of copy are still finding the fair price point. In addition, the most effective bounty amount could vary based on the site. In crowedsourcing platform 'how to perform crowdsourcing?' is identified. There are two approaches; whether using available platforms or develop a new crowdsource platform. Objective of this phase is to have a platform where tasks are available to the participants and to know how platform will work. To have right platform is very crucial for the project. There are the sites that do specific kind of work. Having a wrong platform can be a disaster.

In Participant Side in Crowdsourcing Process a worker firstly searches for a task that he/she is interested in. After such a task is found, the worker makes a decision whether or not to accept it. If the task is accepted, the worker starts working on the task. Otherwise, the worker keeps searching for another task. After the worker finishes the task, the worker submits it for evaluation by the requester. These four actions of a worker correspond to four performance metrics respectively, that is, accepting time, acceptance, working time, and accuracy some cases are observed where the workers accept multiple tasks and work on them at a later time. This behavior is not captured in this simplified model.

\subsection{Case Studies}

For the better understanding of crowdsourcing practice in Pakistan, some open-end interviews were arranged with 3 well reputed organizations of Pakistan and results gathered helped to understand crowdsourcing practice, some of the risks associated with it and how they manage those risks. Few events are mentioned bellow:

\subsubsection{Case study 1: Lipton-Unilever}

"In October 2010, we revealed an 'Ability Hunt', running an opposition in different colleges, with an undertaking to assemble a fan page predictable with the brand's slogan. With contending groups browsed seven driving business colleges, the enlistment procedure acknowledged all the marketable strategies submitted inside the distributed spending plan for executing a web- based social networking effort inside three weeks. It in a flash turned into a hit due its particular target showcase, the instructive establishments with the most elevated number of online networking clients" "we propelled another occasion alongside above occasion which was a "Make the Ad" rivalry. We requested that our fans make an electronic advertisement around one of our items. We reported appealing presents for champs and runners up. That worked truly well as an advertising instrument for our customers and we got various promotions. This action was reached out for over a month which got us a promotion, which we needed; it got us a large number of fans, a well form fan page and furthermore created energetic association."

\subsubsection{Case study 2: UET Lahore and KFC collaboration}

A main college UET as a team with a fast food chain (KFC) propelled an interuniversity promotion making rivalry. Understudies were welcome to make an electronic advertisement of the brand and get a shot of winning Rs50,000 in real money. The battle was advanced on Social Media fan pages and gatherings of the college as well as the brand. Every member additionally helped in advancing the crusade by posting the promotions and updates on their own online networking profiles. This turned out to be an enormous accomplishment as understudy life does involves eating out with companions and having a ton of fun - henceforth the methodology of group sourcing hit a bulls eye by choosing the best target crowd. Their concept of group sourcing worked truly well for them.

\subsubsection{Case study 3: ZONG pre-launch campaign}

One of Pakistan's Leading versatile system organization ZONG propelled itself with the assistance of crowdsourcing. Declarations were made through electronic and in addition print media requesting that the gathering of people recommend a name for the brand. It ran a crusade for right around a month and after that at last thought of a name as recommended by the group of onlookers with most extreme number of votes. This movement picked up the brand a considerable measure of clients even before being really propelled. 


\subsubsection{Adaption and relevance of Crowdsourcing to different departments}

Respondents were made a request to state whether they thought crowdsourcing models prescribed appropriate way to deal with various divisions. Overwhelmingly, the R\&D office was the most referred to, showcasing and deals taken after behind. While data innovation was a far off third and HR and operations were fourth. The discoveries mirror the general conviction that crowdsourcing is to a great extent significant to advancement, seeing as R\&D was the mindboggling top choice. They additionally show that the utilization of crowdsourcing is a troublesome component for each office inside an association.

\subsection{Crowdsourcing Process Model Application on Case Studies}

This section describes the application of proposed crowdsourcing model on the selected case studies. Each case study's in terms of crowdsourcing process activities is discussed below:

Case 1 discusses 'talent hunt' program launch and its objective. Process model defines 'selecting task to be crowdsourced' as a starting activity. First it is decided that what to crowdsource, in case 1 'fan page building' consistent with brand's tagline is the task which is being crowdsourced. Now it has to be decided what crowdsourcing approach should be used, as it is a talent hunt so competition based crowdsourcing approached is used. Process model further classifies competition based crowdsourcing into three models. Crowd-expert sentimental, crowd decision and expert decisions are three models of competition based crowdsourcing. Next step is to decide crowdsourcing platform, either to develop own crowdsourcing platform and invite crowd or use already existing platforms. In present case, task is upload and all the related information like time duration, prize money, fan page requirements, ad's requirements and all other related information is provided. Task is now made available to the crowd. On the participant side's, participant search tasks of his/her interest. He/she book task made available by the Lipton company. If he/she has any queries, he asks intermediary or company.

On company side, quick feedback is made sure to entertain participants' queries. One best idea is selected by the company and winner is awarded with the declare bounty amount. Lipton 'talent hunt' program is closed once winner is declared.

Case 2 discusses 'ad making' competition undertaken interuniversity (UET Lahore) with collaboration of a fast food chain KFC. Process model defines 'selecting task to be crowdsourced' as a starting activity. First it is decided that what to crowdsource, in case 2 'make ad for brand' is the task which is being crowdsourced. Process model further classifies competition based crowdsourcing into three models. Crowd-expert sentimental, crowd decision and expert decisions are three models of competition based crowdsourcing. In case 2, expert decision model is used. Participants will submit their tasks/work and expert of the organization will decide the winning task. As there are two organizations involved in one competition, but ad is being made for KFC so its SME will choose the best work. Next step is to decide crowdsourcing platform, either to develop own crowdsourcing platform and invite crowd or use already existing platforms. In case 2, already existing university portal and social media profiles are used as crowdsourcing platforms. Task is upload on the portal and promoted on social media site and all the related valuable information is provided like time duration, prize money and ad's requirements. Task is now made available to the crowd. On the participant side's, students of university seek to participate the competition. They start working on ad making for the brand. If they have any queries, they ask intermediary or company via platform or provided ways to contact. On company side, quick feedback is made sure to entertain students' queries. One best ad is selected by the brand and winner is awarded with the declare bounty amount. After winner is declared and UET and KFC close out competition in a thorough manner. Selected ad is further evaluated and documentation of the process is made. Lesson learned by the company are also documented for future practices. At the end, final assessment of the financial impact, innovation level, and turnaround time of the project is done.

Case 3 discusses 'ZONG pre-launch campaign'. Process model defines 'selecting task to be crowdsourced' as a starting activity. First it is decided that what to crowdsource, in case 3 'brand name' is asked from the crowd and crowd is being invited to suggest brand name. Now as per process model, it has to be decided what crowdsourcing approach should be used, as it is sort of crowdcontest so competition based crowdsourcing approached is also used for this case. Process model further classifies competition based crowdsourcing into three models. Next step is to decide crowdsourcing platform, either to develop own crowdsourcing platform and invite crowd or use already existing platforms. In case 3, existing crowdsource platform is decided to go with as announcements will be made through electronic media. After selecting crowdsourcing platform task is upload on the site and all the related information is provided. In present case, task is upload and all the related information like time duration, prize money and all other related information about cellular company is provided. Task is now made available to the crowd. On the participant side's, participant search tasks of his/her interest. They suggest the brand name and If they have any query, they ask intermediary or company. On company side, quick feedback is made sure to entertain participants' queries. After winner is declared and company close out campaign in a thorough manner. Selected brand name is evaluated and documentation of the process is made which can be used in future practices. At the end, final assessment of the financial impact, innovation level, and turnaround time of the project is done. 


\section{Risk Management}

Use of crowdsourcing in literature is termed as creative and as a decent apparatus for decreasing danger, however in some cases likewise as a hotspot for extra hazard elements (Schenk and Guittard 2009). It is critical to do a legitimate hazard administration procedure to recognize dangers, asses those hazard, treat those dangers and screen and control such hazard. Recognizable proof of the interrelationships of dangers elements with procedures and structures of crowdsourcing model is important to learn and perform. Dangers emerging from a negative recognition with respect to clients, counterparties, shareholders, financial specialists or controllers can antagonistically influence an association's capacity to keep up existing, or set up new, business connections and proceeded with access to wellsprings of learning and wellsprings of subsidizing. Thusly, keeping a high notoriety is of most extreme significance to relieve these dangers, and notoriety is an aftereffect of satisfactory administration of dangers related the crowdsourcing advancement business.

\subsection{Determination of Risks Involved}

For the better understanding of crowdsourcing practice in Pakistan, some open-end interviews were arranged with the 3 well reputed organization and When asked about 'why crowdsourcing practices are still not very common in Pakistan?' and 'what risks do you think an organization can face while practicing crowdsourcing?. Data collected revealed the crowdsourcing's risks experienced and observed by practitioners. These risks include: turbulence risk, risk of leaking confidential information to the crowd; employment issues; IP and patent issues; quality issues; and participation risks. All the risks identified by practitioners in cases which are being studied in this study are as follows, these risks are further divided into their certain risk dimension to make risk management easy and convenient. Risk dimensions are turbulence, organizational/societal, financial, low motivation and quality risks,

- Unpredictability of the crowd

- Brand destruction

- Reputation risks

- IP ownership risks

- Confidentiality risks

- Employment law issues

- Resistance by employees

- Lack of acceptance by managers \& departments

- Legal and regulatory changes

- Related to quality risks

- Low participation risk

- Quality risks

\subsection{Risk Assessment}

After recognizable proof of dangers, hazard investigation is the following stride. It includes quantitative or subjective hazard evaluation. Subjective Risk Analysis is the way toward organizing dangers for further examination or activity by evaluating and joining their likelihood of event and effect. The key advantage of this procedure is that it empowers extend directors to lessen the level of instability and to concentrate on high-need dangers. The achievement of the assessment is given by the way it is recorded and abridging the information to be handled. There are diverse devices and strategies for subjective hazard examination which incorporates chance likelihood and effect appraisal, likelihood and effect lattice, chance information quality evaluation, chance arrangement, chance direness evaluation and master judgment. In this exposition, likelihood and effect framework is being utilized to compute chance level. Taking after table shows how effect is being broke down.

Table 1. Impact Analysis

\begin{tabular}{|l|l|l|}
\hline Magnitude of impact & Impact definition & Score \\
\hline High impact/ High probability & $\begin{array}{l}\text { Very High } \\
\text { Risk exposure is high, require good management } \\
\text { and close monitoring }\end{array}$ & 5 \\
\hline $\begin{array}{l}\text { High impact/ Medium probability Medium } \\
\text { impact/ High probability }\end{array}$ & $\begin{array}{l}\text { High } \\
\text { Risks have either high probability or } \\
\text { significant impact, need immediate mitigation }\end{array}$ & 4 \\
\hline $\begin{array}{l}\text { Medium impact/ Medium } \\
\text { probability }\end{array}$ & $\begin{array}{l}\text { Medium } \\
\text { Risk exposure is moderate, need regular } \\
\text { monitoring }\end{array}$ & 3 \\
\hline
\end{tabular}




\begin{tabular}{|l|l|l|}
\hline $\begin{array}{l}\text { Medium impact/ Low probability Low } \\
\text { impact/ Medium probability }\end{array}$ & $\begin{array}{l}\text { Low } \\
\text { Risk occurrence chances are low, risk exposure } \\
\text { can be low or significant. }\end{array}$ & 2 \\
\hline Low impact/ Low probability & $\begin{array}{l}\text { Insignificant } \\
\text { Negligible }\end{array}$ & 1 \\
\hline
\end{tabular}

Table 2. Likelihood/probability score

\begin{tabular}{|l|l|l|}
\hline Likelihood level & Description & Score \\
\hline Frequent & Will undoubtedly happen or recur, possibly frequently. & 5 \\
\hline Likely & $\begin{array}{l}\text { Will probably happen or recur, but it is not a persisting issue / } \\
\text { circumstance }\end{array}$ & 4 \\
\hline Occasional & Might happen or recur occasionally & 3 \\
\hline Unlikely & Do not expect it to happen or recur but it is possible it may do so & 2 \\
\hline Rare & Will probably never happen or recur & 1 \\
\hline
\end{tabular}

Table 3. Probability Impact Matrix

\begin{tabular}{|l|l|l|l|l|l|}
\hline \multirow{2}{*}{$\begin{array}{l}\text { Probability/ } \\
\text { likelihood }\end{array}$} & \multicolumn{4}{|l|}{ Impact } \\
\cline { 2 - 6 } & $\begin{array}{l}\text { Very } \\
\text { high 5 }\end{array}$ & High 4 & Medium 3 & $\begin{array}{l}\text { Low } \\
\text { 2 }\end{array}$ & Insignificant 1 \\
\hline 5 Frequent & Extreme & Extreme & Extreme & High & High \\
\hline 4 Likely & Extreme & Extreme & High & Moderate & Moderate \\
\hline 3 Occasional & Extreme & High & High & Moderate & Low \\
\hline 2 Unlikely & High & High & Moderate & Low & Low \\
\hline 1 Rare & Moderate & Moderate & Low & Low & Low \\
\hline
\end{tabular}

Risk level $=$ impact $*$ probability

Table 4. Risk Evaluation Criteria

\begin{tabular}{|l|l|}
\hline Assessment Risk Index & Criteria \\
\hline Extreme & Unacceptable, requires immediate action \\
\hline High & Manageable under risk control and mitigation \\
\hline Moderate & Acceptable after review, Requires continued tracking \\
\hline Low & $\begin{array}{l}\text { Acceptable with continued data collection, necessary to keep } \\
\text { track }\end{array}$ \\
\hline
\end{tabular}

\section{Risks Management Application on Case Studies}

\subsection{Case Study 1: Risks and Management Measures}

In Lipton talent hunt case study, competition- based crowdsourcing was done. Practitioners faced certain risks while conducting a competition for ad making and fan page consistent with brand's tagline. One of the major risks stated by respondents was turbulence risk as in terms of IP ownership risk and confidentiality risk. Another risk stated by practitioners was quality risk. And when competition-based crowdsourcing is being practices, financial risks also get along as they are connected to quality risks. Table below shows the risks identified in case 1:

Table 5. Risks in Case study 1

\begin{tabular}{|l|l|}
\hline Risk Dimension & Risk \\
\hline Turbulence Risk & $\begin{array}{l}\text { IP ownership Risk } \\
\text { Confidentiality Risk } \\
\text { Unpredictability of the crowd }\end{array}$ \\
\hline Quality Risks & Quality risks \\
\hline Financial Risks & Quality risks \\
\hline
\end{tabular}




\subsubsection{Turbulence risk}

The significance of turbulence dangers relates to the unusualness and expanding intricacy of the business condition. These dangers are normally experienced by huge scale organizations because of unanticipated components (European Commission 2010). Turbulence risks, which are because of vulnerability, could emerge out of the accompanying unusualness of the group and absence of control of the jam and may bring about:

- Conceivable weakening or annihilation of the brand or venture.

- Individuals required in crowdsourcing forms begin having more impact on brands or tasks, different clients and the media.

- $\quad$ Disruptively affecting business both in a positive and negative way

Confidentiality risk are real dangers related with turbulence. Security dangers associated with crowdsourcing are principally engaged around the danger of releasing delicate data to people in general and even to contenders. To use crowdsourcing systems, firms of need to discharge some applicable data as crude material for the group to work with. As a rule, particularly those including advancement, such data incorporates pieces of licensed works which the profiting firms spent fortunes to gain. Discharging them to the group - notwithstanding when the group is a controlled one - is a noteworthy hazard which most firms are unwilling to.

Turbulence Risk management:

So as to keep the jam in accordance with the goals of the crowdsourcing model and turbulence chances in pace, a few of the respondents proposed the accompanying:

- Ensure that the organization permits business pioneers and controlling partners to make a definitive call with respect to advancement pathways. All venture participant(s) should be included and prepared to limit hazards as opposed to seeing open doors.

Figure out how to picture the collaborations and creations of your group - make this effectively accessible and improvable by the group itself.

\subsubsection{Quality Risks}

Respondents were exceptionally worried about conceivable quality dangers. Since the assignment could be apportioned to individuals they don't have the foggiest idea about, the customers or requesters are presented to major issues with respect to the nature of results. Member concerns included:

- Wasting time and not creating sensible outcomes

- Getting undesirable outcomes

- Difficulty of controlling the quality

- Need to filter through a few entries to discover profitable information

- Concerns about the nature of crowdsourcing members

Quality risk management:

Conceivable hazard administration measures proposed by the professionals include:

- Defining quality levels and settled remuneration for these levels

- Spending time to plainly characterize the assignment

- Using a community oriented, instead of an aggressive model

- Entry assessment of member

- Task replication

- $\quad$ Ensuring more prominent interest

- Tracking group laborers' execution (on- going quality control of work).

- Having individuals to encourage the procedure.

- Automated quality control.

- Building your own group of branches of knowledge specialists

\subsubsection{Financial Risks}

The outcomes show that money related dangers are tied with quality dangers. A few reactions mirror the worry of a few organizations to fund a crowdsourcing model because of the conceivable money related misfortunes that an unsuccessful crowdsourcing practice may bring about. One of the response was: 'Yes, it is a risky process if it does not 
manage well. It can have a financial risk for the company who like to give reward to the crowd and risk of not attracting the crowd for future project if it fails in motivating them at first.'

Financial Risks management:

The financial risks are related to quality risks, risk management measures suggested in the quality risks section are also applied to the financial risks, such as tracking a crowd member's performance, ensuring greater participation, use of collaborative models, and entry evaluation, among others.

\subsubsection{Risk Assessment}

Turbulence Risk Level:

Turbulence hazard was seen by the respondents as the most serious danger of crowdsourcing. Turbulence chances emphatically show change and its need of being overseen legitimately. Turbulence dangers, which are because of vulnerability, could emerge in light of unusualness of the group and absence of control of the group. The professionals expressed that the effect of an uncontrolled group on the brand is conceivably unfriendly. At the point when gotten some information about the probability of event, respondents expressed that it might be periodic however not visit.

Matrix for turbulence risk:

Impact is very high and probability is occasional.

Table 6. risk level

\begin{tabular}{|c|c|c|c|c|c|}
\hline \multirow{2}{*}{$\begin{array}{l}\text { Probability/ } \\
\text { likelihood }\end{array}$} & \multicolumn{5}{|l|}{ Impact } \\
\hline & $\begin{array}{l}\text { Very } \\
\text { high } 5\end{array}$ & $\begin{array}{l}\text { High } \\
4\end{array}$ & Medium 3 & $\begin{array}{l}\text { Low } \\
2\end{array}$ & Insignificant 1 \\
\hline \multicolumn{6}{|l|}{ 5-- Frequent } \\
\hline \multicolumn{6}{|l|}{ 4-- Likely } \\
\hline 3-- Occasional & 15 & & & & \\
\hline \multicolumn{6}{|l|}{ 2-- Unlikely } \\
\hline 1-- Rare & & & & & \\
\hline
\end{tabular}

So, according to the criteria, turbulence risk is extreme. It is unacceptable under current circumstances and it requires immediate action.

Quality risk level:

The conceivable component prompting low quality is absence of legitimate rules and headings on how the assignment is to be finished, bringing about laborers not understanding the asked for errand. The review members likewise perceive this as a conceivable cause.

Respondents expressed that quality work is a definitive desire of any association or person when they decide to crowdsource their work. So, it's a big risk if they couldn't generate quality work. Impact is high but due to proper control, continuous tracking and having appropriate crowd at first place will not let this quality risk generate.

Matrix for quality risks:

Impact is high but occurrence likelihood is unlikely.

Table 7. Quality risks

\begin{tabular}{|l|l|l|l|l|l|}
\hline \multirow{2}{*}{$\begin{array}{l}\text { Probability/ } \\
\text { likelihood }\end{array}$} & \multicolumn{4}{|l|}{ Impact } \\
\cline { 2 - 6 } & $\begin{array}{l}\text { Very } \\
\text { high 5 }\end{array}$ & $\begin{array}{l}\text { High } \\
\mathbf{4}\end{array}$ & Medium 3 & $\begin{array}{l}\text { Low } \\
\mathbf{2}\end{array}$ & Insignificant 1 \\
\hline 5-- Frequent & & & & & \\
\hline 4-- Likely & & & & & \\
\hline 3-- Occasional & & & & & \\
\hline 2-- Unlikely & & $\mathbf{8}$ & & & \\
\hline 1-- Rare & & & & & \\
\hline \\
Risk level =4*2=8
\end{tabular}

So, according to set criterion such risks are high and are manageable under risk control and mitigation. These risks require risk analysis board $(\mathrm{RAB})$ and management decisions.

Financial risk level:

As indicated by the respondent's reactions it is inferred that the more evident budgetary hazard that organizations may bring about includes those organizations that utilization the paid crowdsourcing approach, since these organizations need to put cash with a specific end goal to get the administration that they require from the group. The dread of monetary misfortune turns into a reality if the group does not convey on the nature of the work required, or if 
the group misses the mark regarding the desires. Impact of such risks is high but they are unlikely to happen because of already proper control over crowdsourcing process being taken out.

Matrix for financial risks:

Impact is high but occurrence probability is unlikely.

Table 8. Financial risks

\begin{tabular}{|c|c|c|c|c|c|}
\hline \multirow{2}{*}{$\begin{array}{l}\text { Probability/ } \\
\text { likelihood }\end{array}$} & \multicolumn{5}{|c|}{ Impact } \\
\hline & $\begin{array}{l}\text { Very } \\
\text { high } 5\end{array}$ & $\begin{array}{l}\text { High } \\
4\end{array}$ & Medium 3 & $\begin{array}{l}\text { Low } \\
2\end{array}$ & Insignificant 1 \\
\hline \multicolumn{6}{|l|}{ 5-- Frequent } \\
\hline \multicolumn{6}{|l|}{ 4-- Likely } \\
\hline \multicolumn{6}{|l|}{ 3-- Occasional } \\
\hline 2-- Unlikely & & 8 & & & \\
\hline 1-- Rare & & & & & \\
\hline
\end{tabular}

So, according to set criterion such risks are high and manageable under risk control and mitigation. These risks require risk analysis board $(\mathrm{RAB})$ and management decisions.

\subsection{Case Study 2: UET and KFC Collaboration}

They also conducted competition based crowdsourcing and students were asked to make an ad for the brand and prize money was declared. Many responses were received by practitioners. It was a successful competition with great result. When asked about risks to the crowdsourcer, they mentioned risk of leakage of confidential information is biggest one. Along with it, brand reputation risk always come along so turbulence risk is biggest risk in crowdsourcing practice. If confidential data is to be provided, reputation risk can occur. Crowdsourcing practitioners were concerned that losing control of the crowd not only loses the benefits of crowdsourcing but also hurts the reputation and image of the brand, which would in turn affect the company's profitability and consumer acceptance. Table 9 bellow shows risks identified in case study 2 :

Table 9. Risks identified in case study 2

Turbulence Risk

\begin{tabular}{|l|l|}
\hline Risk dimension & Risk \\
\hline Turbulence Risk & $\begin{array}{l}\text { Brand destruction } \\
\text { Reputation risks } \\
\text { Confidentiality risks }\end{array}$ \\
\hline Organizational/societal Risk & Acceptance Risk \\
\hline
\end{tabular}

Turbulence risk has been explained earlier in case mentioned in case study 1, some different measures mentioned were:

- Restricting access by login type.

- Anonymizing the data so that it becomes more neutral when released to the crowd.

- Breaking down a big project into smaller elements

Organizational/societal risk:

Risks in this dimension are:

- Employment law issues

- Resistance by representatives

- Lack of acknowledgment by chiefs and divisions

- Legal and administrative changes

Managing Organizational/Societal risk:

Following management measures were stated by respondents: 
- Copyright and benefit assertions

- Building an "advancement mentality" inside the association

\subsubsection{Risk Assessment}

Turbulence Risk Level:

Turbulence risk was seen by the respondents as the greatest risk of crowdsourcing in case study 2 . When asked about the likelihood of occurrence, respondents stated that it may be occasional but not frequent but if occur, it has very high impact.

Matrix for turbulence risk:

Impact is very high and probability is occasional. Management measures stated by practitioners in case study 2 were almost same as study 1 .

Table 10. Turbulence Risk (case study 2)

\begin{tabular}{|l|l|l|l|l|l|}
\hline \multirow{2}{*}{$\begin{array}{l}\text { Probability/ } \\
\text { likelihood }\end{array}$} & \multicolumn{2}{|l|}{ Impact } \\
\cline { 2 - 6 } & $\begin{array}{l}\text { Very } \\
\text { high 5 }\end{array}$ & $\begin{array}{l}\text { High } \\
\mathbf{n}\end{array}$ & Medium 3 & $\begin{array}{l}\text { Low } \\
\mathbf{2}\end{array}$ & Insignificant 1 \\
\hline 5-- Frequent & & & & & \\
\hline 4-- Likely & & & & & \\
\hline 3-- Occasional & 15 & & & & \\
\hline 2-- Unlikely & & & & & \\
\hline 1-- Rare & & & & & \\
\hline Risk level: 5*3 15 & & & & & \\
\hline
\end{tabular}

So, according to the criteria, turbulence risk is extreme. It is unacceptable under current circumstances and it requires immediate action.

Organizational/ societal risk level: Authoritative/societal dangers incorporate business law dangers, lawful administrative changes and resistance by representatives or directors. As indicated by respondents, there is need in locale and enactment that must be shut sooner rather than later. There is no relief for such dangers, since they are certain to the idea of crowdsourcing. In any case, if everybody willfully utilizes "best practices" in pay would moderate such dangers. These dangers are not extremely basic in light of the fact that an association normally consent to an arrangement which by one means or another shield from such dangers. They are uncommon yet their effect is high.

Matrix for organizational/ societal risks:

Impact is high but occurrence likelihood is rare.

Table 11. Organizational/ societal risks (case study 2)

\begin{tabular}{|l|l|l|l|l|l|}
\hline \multirow{2}{*}{$\begin{array}{l}\text { Probability/ } \\
\text { likelihood }\end{array}$} & \multicolumn{2}{|l|}{ Impact } \\
\cline { 2 - 6 } & $\begin{array}{l}\text { Very } \\
\text { high } \\
\mathbf{5}\end{array}$ & $\begin{array}{l}\text { High } \\
\mathbf{4}\end{array}$ & Medium 3 & $\begin{array}{l}\text { Low } \\
\text { 2 }\end{array}$ & Insignificant 1 \\
\hline 5-- Frequent & & & & & \\
\hline 4-- Likely & & & & & \\
\hline 3-- Occasional & & & & & \\
\hline 2-- Unlikely & & & & & \\
\hline 1-- Rare & & 4 & & & \\
\hline Risk level =4*1=4 & & & & & \\
\hline
\end{tabular}

So, according to set criterion such risks are moderate. They are acceptable after reviewing the operation. They require continuous tracking and recorded action plans.

\subsection{Case Study 3: Zong Pre-Brand Launch Campaign}

In this case, a whole new brand was about to get launched and company approached crowd to suggest a brand name. It was a total new experience to practitioners but they were hopeful for having a good brand name in result. They did get succeed as they receive huge response from the crowd. When asked about their risks before the campaign, 
practitioners responded that biggest risk was unacceptably of the idea by crowd or by the managers. What if crowd is not responsive and what if there is low motivation among participants as crowd is very unpredictable. Table 8 shows the risks identified in case study 3 :

Table 12. Risks identified in case study 3

\begin{tabular}{|l|l|}
\hline Risk dimension & Risk \\
\hline Turbulence Risk & Crowd unpredictability \\
\hline Organizational/societal risk & Acceptability Risk Employment law issues \\
\hline Low participation Risk & Low motivation \\
\hline
\end{tabular}

Turbulence risk and organizational/societal risks had already been explained in case study 1 and case study.

Low participation:

The respondents additionally viewed crowdsourcing activities as hazardous as far as low investment. The members regarded the low cooperation to be because of various components, for example,

- Lack of attention to the crowdsourcing activity.

- $\quad$ Lack of clear correspondence between the requester and the group.

- $\quad$ Lack of comprehension of how to spur the specific group

Motivation risk management:

Recommendations from professionals concentrate on group administration - control of the group, and setting aside greater opportunity to structure a roused and devoted group. Such recommendation from the respondents is upheld by research, especially by Garry (2010), who contended that while a pack cooperates for a brief length and a shared objective, a group is constantly together, regardless of whether there is motivation to cooperate or not.

\subsubsection{Risk Assessment}

Turbulence risk:

When asked about turbulence risk likelihood of occurrence and impact, respondents of case study 3 stated that it is likely to occur but if occur, it has very high impact.

Table 13. Risk Assessment (case study 3)

\begin{tabular}{|c|c|c|c|c|c|}
\hline \multirow{2}{*}{$\begin{array}{l}\text { Probability/ } \\
\text { likelihood }\end{array}$} & \multicolumn{5}{|l|}{ Impact } \\
\hline & $\begin{array}{l}\text { Very } \\
\text { high } 5\end{array}$ & $\begin{array}{l}\text { High } \\
4\end{array}$ & Medium 3 & $\begin{array}{l}\text { Low } \\
2\end{array}$ & Insignificant 1 \\
\hline \multicolumn{6}{|l|}{ 5-- Frequent } \\
\hline 4-- Likely & 20 & & & & \\
\hline \multicolumn{6}{|c|}{ 3-- Occasional } \\
\hline \multicolumn{6}{|l|}{ 2-- Unlikely } \\
\hline 1-- Rare & & & & & \\
\hline
\end{tabular}

Risk level: $5 * 4=20$

So, according to the criteria, turbulence risk is extreme. It is unacceptable under current circumstances and it requires immediate action.

Organizational/ societal risk:

These risks are not very common because an organization usually sign an agreement which somehow protect from such risks. They are rare but their impact is high.

Matrix for organizational/ societal risks: Impact is high but occurrence likelihood is rare.

Table 14. Societal risks (case study 3 )

\begin{tabular}{|l|l|l|l|l|l|}
\hline \multirow{2}{*}{$\begin{array}{l}\text { Probability/ } \\
\text { likelihood }\end{array}$} & \multicolumn{2}{|l|}{ Impact } \\
\cline { 2 - 5 } & $\begin{array}{l}\text { Very } \\
\text { high 5 }\end{array}$ & High 4 & Medium 3 & Low 2 & Insignificant 1 \\
\hline
\end{tabular}




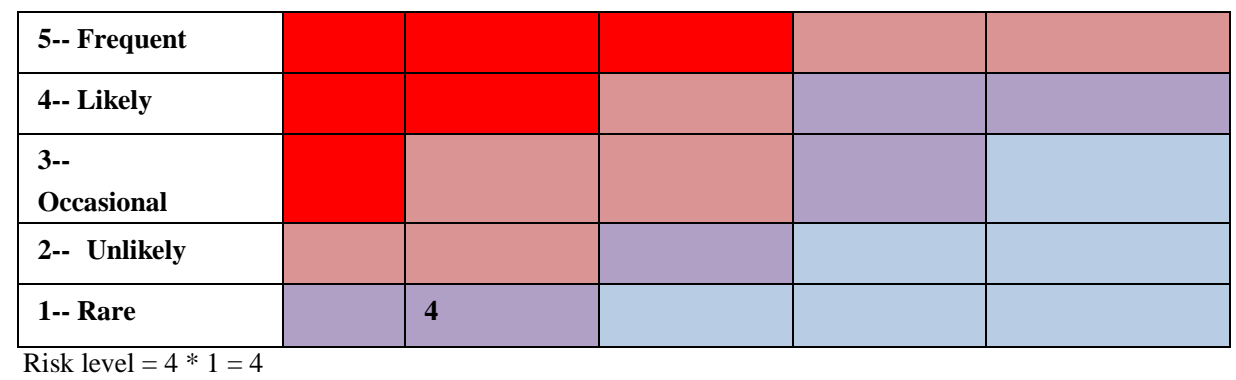

So, according to set criterion such risks are moderate. They are acceptable after reviewing the operation. They require continuous tracking and recorded action plans.

Low Participation risk level:

Every one of the respondents perceive that inspiration is the key driver of keeping a group dynamic. The rousing components to get crowdsourcing to work are acclaim, fortune, fun, and satisfaction. These variables will call individuals to take part as volunteers for crowdsourcing.

It is uncommon to have such dangers since firms crowdsource their work to get great and quality outcomes and for that they give every single conceivable direction and clear rules to the group. In results, swarm stays drawn in to the errand. Also, if there is low cooperation from the group, there still are great opportunities to have quality outcomes since it regards have less however proper group.

Matrix for low participation risks:

Impact is low and probability is rare.

Table 15.Low participation risk

\begin{tabular}{|c|c|c|c|c|c|}
\hline \multirow{2}{*}{$\begin{array}{l}\text { Probability/ } \\
\text { likelihood }\end{array}$} & \multicolumn{5}{|c|}{ Impact } \\
\hline & $\begin{array}{l}\text { Very } \\
\text { high } 5\end{array}$ & High 4 & Medium 3 & Low 2 & Insignificant 1 \\
\hline \multicolumn{6}{|l|}{ 5-- Frequent } \\
\hline \multicolumn{6}{|l|}{ 4-- Likely } \\
\hline \multicolumn{6}{|l|}{ 3-- Occasional } \\
\hline \multicolumn{6}{|l|}{ 2-- Unlikely } \\
\hline 1-- Rare & & & & 2 & \\
\hline
\end{tabular}

So, according to criteria defined, such risks are acceptable with continued data collection.

\subsection{Risk Treatment/ Response}

In summary of all identified risks and their management measures, it is a procedure to adjust or react to a hazard. The motivation behind the hazard reaction step is to choose, in light of the consequences of hazard examination, which dangers and openings require a reaction and what suggested reaction will be. The kind of hazard treatment picked will frequently rely on upon the way of the hazard and the resistance for that hazard. Turbulence risks' score is 15 having impact score 5 and probability 3, which make it adverse risk if occurred. So, it can't be avoided or transferred. It is necessary to accept such risks and treat them appropriately. Methods and strategies can be applied to reduce the likelihood of occurrence.

Quality risks' score is 8 with impact score 4 and probability score 2 . These risks require mitigation strategies to reduce their consequences and impact. They can't be avoided. Financial risks are linked with quality risks. Their risk score is 8 which make them unavoidable. They need mitigation to reduce their each hazard's score/level (effect * likelihood) decide reaction each hazard will get. Process:

- Decide if particular treatment is fundamental or whether the hazard can be enough treated over the span of standard administration methodology and exercises; that is, implant the treatment into day-today practices or procedures. In surveying what medications could be executed, it is valuable to consider routes in which standard practices as of now fill in as a control, or courses in which those standard practices could be changed to enough control the hazard.

- Determine what the objective is in treating this specific hazard; is it to stay away from it totally, diminish the probability or outcome, exchange the hazard (to another person, for example, a safety net provider or temporary worker) or acknowledge the level of hazard in view of existing data? The consequences. Organizational/ societal risks' score is 4 with impact score 2 and probability score 2 . These risks are of 
moderate nature. They can be transferred or mitigated. They can be crucial if not been taken care and tracked continuously so because if such nature, they can't be avoided. Low participation risk's score is 2 with impact score 2 and probability 1 . They can be avoided or transferred. They don't necessarily require acceptance and mitigation.

\subsection{Monitor and Control Risk}

Understand that the idea of hazard is dynamic and necessities occasional and formal audit. The money of recognized dangers should be routinely checked. New dangers and their effect on the association may to be considered. when dangers have been recognized, recorded, examined, and the concurred medications have been actualized, a proper checking and detailing administration should be set up to give confirmation that the treatment has been powerful and now controls the hazard.

\section{Findings}

Value is the limit of a decent, administration, or action to fulfill a need or give an advantage to a man or lawful substance. This meaning of significant worth is plainly more extensive than the conventional definition utilized by a few market analysts. It incorporates any kind of good, administration, or act that fulfills a need or gives an advantage, which might be substantial or impalpable, including those that emphatically add to the personal satisfaction, information, glory, money related security, and also giving sustenance, protect, transportation, salary, and so on. Value creation is the essential point of any business substance. Making an incentive for clients offers items and administrations, while making an incentive for shareholders, as increments in stock cost, guarantees the future accessibility of venture cashflow to store operations. Value creation is progressively being perceived as a superior administration objective than strict monetary measures of execution, a considerable lot of which tend to place cost- stopping that produces term comes about in front of ventures that upgrade long haul aggressiveness and development.

\subsection{Value Creation in Crowdsourcing Context}

The goal of every organization is to create value through its various activities. This remains true in the case of outsourcing. In this chapter, we will attempt to explain how a company can create value by means of a crowdsourcing operation. Value is created through a process as being a source. In the process, number of activities are performed that leads to the creation of value for stakeholders.

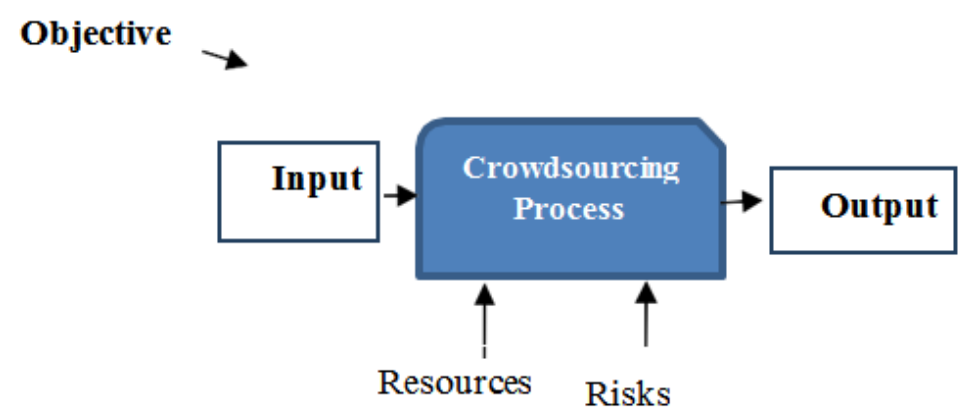

Fig.5.

\subsection{Empirical Study}

In this section, the process for case selection is firstly opened up, then followed by presentation of the empirical findings from the multiple case study.

\subsubsection{Case selection:}

Cases are selected randomly from the cases in Pakistan in which crowdsourcing is being practiced. Crowdsourcing platforms that were company internal, under development, discontinued, not released at the moment or difficult to receive information from were not included in the process of case selection. The sources of data used for the case studies evaluation were researched and direct observations. The research included available crowdsourcing literature, conference papers, and various Internet sources. Direct observation was made in form of visiting different organizations which are practicing crowdsourcing. All the cases are briefly described in above section 'crowdsourcing practice in Pakistan'. The cases were selected to cover all value generation sources. The cases, which provided the most information for the value generation sources were chosen with the aim to gain the greatest possible amount of information to answer the research question. 


\subsection{Empirical Findings}

The key empirical findings from the three selected cases are opened up in next section through the Amit and Zott (2001) model.

\subsubsection{Novelty}

In all cases, it could be watched that crowdsourcing associated already detached gatherings inside one stage to share their insight and innovativeness. Lipton launched talent hunt and 'make an ad competition' in total new environment outside the organization connecting with different audience. UET Lahore launched interuniversity admaking competition with collaboration of fast food chain KFC. ZONG Pakistan connected to audience via electronic media campaign. Bits of knowledge of the jam can be used novelty to distinguish drifts by gathering client criticism. Table below shows which value attribute of novelty is present in specific case and is generating value.

Table 16. Novelty mapping over cases

\begin{tabular}{|l|l|l|l|}
\hline \multicolumn{1}{|l|}{ Cases } & \multicolumn{2}{|l|}{ Novelty attributes } \\
\cline { 2 - 4 } & $\begin{array}{l}\text { New transactional } \\
\text { structure }\end{array}$ & $\begin{array}{l}\text { New transactional } \\
\text { content }\end{array}$ & New participants \\
\hline Case 1: Lipton & $\mathbf{X}$ & $\mathbf{X}$ & $\mathbf{O}$ \\
\hline $\begin{array}{l}\text { Case 2: UET \& KFC } \\
\text { collaboration }\end{array}$ & $\mathbf{X}$ & $\mathbf{X}$ & $\mathbf{O}$ \\
\hline Case 3: ZONG & & & $\mathbf{X}$ \\
\hline
\end{tabular}

In Table 16, the $\mathrm{X}$ means novelty attribute is present is case. Whereas $\mathrm{O}$ refers to absence of that the specific attribute.

\subsubsection{Efficiency}

There are a few perspectives that expansion effectiveness of the preparing of exchanges by crowdsourcing, which are basic for each of the three cases. As a matter of first importance, crowdsourcing empowers to achieve a tremendous measure of individuals regardless of where they originate from by means of virtual group or disconnected group. For instance, more than 1000 people participated in Lipton talent hunt and more than 300 people submitted their ideas in 'ad making competition'.

Whereas more than 1500 students participated in interuniversity competition launched by UET Lahore and prize money declared played vital role in attracting participants. Such tremendous measure of submitted thoughts, input, learning and abilities creates a great deal more esteem and quicken new item advancement handle than without crowdsourcing. Exchange expenses can be brought down by crowdsourcing, in light of the fact that organizations spare time to scan for proper supplier of arrangements, thoughts or data (Amit and Zott, 2001) since the organizations issue an open call. Table below shows which value attribute of efficiency is present in specific case and is generating value.

Table 17. Efficiency mapping over cases

\begin{tabular}{|l|l|l|l|}
\hline \multirow{2}{*}{ Cases } & Efficiency attributes & Scale economics & Simplicity \\
\cline { 2 - 4 } & Symmetric information & $\mathbf{X}$ & $\mathbf{X}$ \\
\hline Case 1: Lipton & $\mathbf{X}$ & $\mathbf{X}$ & $\mathbf{X}$ \\
\hline $\begin{array}{l}\text { Case 2: UET \& KFC } \\
\text { collaboration }\end{array}$ & $\mathbf{X}$ & & \\
\hline Case 3: ZONG & & $\mathbf{X}$ & $\mathbf{X}$ \\
\hline
\end{tabular}

In Table above, the $\mathrm{X}$ means novelty attribute is present is case. Whereas $\mathrm{O}$ refers to absence of that the specific attribute.

\subsubsection{Complementarities}

Crowdsourcing itself is one case of complementarities. Frequently complementarities are identified with effectiveness. Amit and Zott (2001) specified that esteem drivers are interrelated and the discoveries of the contextual analyses approve this. Lipton utilized crowdsourcing to create thoughts for a promotion of one of the results of the organization, UET in a joint effort with KFC likewise focused on gathering of people looking for an advertisement for the brand and crowdsourcers in ZONG contextual investigation utilized electronic media to run a crusade for brand name and made significantly more fans before its official dispatch. Besides, the group offers numerous correlative ideas, 
thoughts or potentially information. All gatherings coordinated in the crowdsourcing procedure advantage by having all associated data, items and administrations on one place. Table below shows which complementarity attribute is present in specific case and is generating value.

Table 18. Complementarities mapping over cases

\begin{tabular}{|l|l|l|l|l|}
\hline Cases & \multicolumn{2}{|l|}{ Complementarities } & \\
\cline { 2 - 5 } & $\begin{array}{l}\text { Between product } \\
\text { and services }\end{array}$ & $\begin{array}{l}\text { Between offline and } \\
\text { online assets }\end{array}$ & Between activities & Between technologies \\
\hline Case 1: Lipton & $\mathbf{O}$ & $\mathbf{X}$ & $\mathbf{X}$ & $\mathbf{O}$ \\
\hline $\begin{array}{l}\text { Case 2: UET \& KFC } \\
\text { collaboration }\end{array}$ & $\mathbf{O}$ & $\mathbf{X}$ & $\mathbf{X}$ & $\mathbf{O}$ \\
\hline Case 3: ZONG & $\mathbf{O}$ & $\mathbf{X}$ & $\mathbf{X}$ & $\mathbf{X}$ \\
\hline
\end{tabular}

In Table above, the $\mathrm{X}$ means novelty attribute is present is case, whereas $\mathrm{O}$ refers to absence of that the specific attribute.

\subsubsection{Lock-in}

Secure is made to draw in clients in making rehashed exchanges (Johansson and Mollstedt, 2006, p. 20). The bits of knowledge that an organization offers with its group bolster the data stream and increment the inspiration of clients and accomplices to take an interest. Lipton for example gave all the data and prerequisites to take an interest in ability chase. Because of particular focused on data and allocated time window of the undertaking, just intrigued individuals presented their business thought. Crowdsourcing stages empower secure by giving a virtual group, which associates all gatherings that are included in the crowdsourcing procedure on one place. All essential data for taking part in the extraordinary crowdsourcing movement is gathered there and can be refreshed. As a rule a simple correspondence between the group and the crowdsourcing organization was empowered by the crowdsourcing stage. Table below shows which value attribute of efficiency is present in specific case and is generating value.

Table 19. Lock-in mapping over cases

\begin{tabular}{|l|l|l|}
\hline Cases & Lock-in \\
\cline { 2 - 3 } & Switching cost & $\begin{array}{l}\text { Positive network } \\
\text { externalities }\end{array}$ \\
\hline Case 1: Lipton & $\mathbf{X}$ & $\mathbf{X}$ \\
\hline $\begin{array}{l}\text { Case 2: UET \& KFC } \\
\text { collaboration }\end{array}$ & & $\mathbf{X}$ \\
\hline Case 3: ZONG & $\mathbf{X}$ & $\mathbf{X}$ \\
\hline
\end{tabular}

In Table above, the $\mathrm{X}$ means novelty attribute is present is case, whereas $\mathrm{O}$ refers to absence of that the specific attribute. Since the way of the vast majority of the cases is non-fiscal and non- material type of remuneration, crowdsourcing is more than in alternate cases driven by a dynamic correspondence among the group. Esteem increments with a developing number of members.

\subsection{Evaluation Criteria}

As the value generation process is qualitatively performed, certain evaluation criteria have to be made on which undesirable, acceptable and desirable values will be classified. Every single attribute of each value source is important in value generation so to decide whether value generated is undesirable, acceptable or desirable below mention criteria is proposed:

- If novelty's all three attributes are present in a case, value generated via this value source is desirable and if one or no attribute is present, value generated is undesirable

- If efficiency's all three attributes are present in a case, value generated via this value source is desirable and if one or no attribute is present, value generated is undesirable

- If complementarity's all four or three attributes are present in a case, value generated via this value source is desirable. If two attributes are present in a case, value generated is acceptable and if one or no attribute is present, value generated is undesirable 
- If lock-in's all attributes are present in a case, value generated via this value source is desirable, if one attribute is present, value generated is acceptable, and of no attribute is present then value generated is undesirable

\subsection{Results}

Based on the application of the theoretical framework (Amit \& Zott 2001) in the empirical case study, the four potential sources of value creation (lock-in, complementarities, efficiency, and novelty) can be adapted for crowdsourcing. Tables below shows the mapping of case studies over framework (Amit \& Zott 2001) and shows value generated via above mentioned value source is either undesirable, acceptable or desirable on the basis of proposed criteria.

Table 20. Value generation assessment of cases

\begin{tabular}{|l|l|l|l|l|}
\hline & Novelty & Efficiency & Complementarities & Lock-in \\
\hline Case 1: Lipton & Acceptable & Desirable & Acceptable & Desirable \\
\hline $\begin{array}{l}\text { Case 2: UET and KFC } \\
\text { collaboration }\end{array}$ & Acceptable & Desirable & Acceptable & Desirable \\
\hline Case 3: ZONG & Desirable & Desirable & Desirable & Desirable \\
\hline
\end{tabular}

Now a criterion has to be proposed on which overall value generation of all the cases will be judged that whether value generated via value sources (Amit and Zott 2001) is desirable, acceptable or undesirable. Every value source plays a Vitol role in value generation. A generalized criterion cannot be set because of diverse nature of the selected cases. So, every case has its own criteria on which value generated is classified into categories like value undesirable, value acceptable or value desirable.

Case study 1:

In Lipton case study, value generated via novelty and complementarity value sources is acceptable and, efficiency and lock-in value sources generated desirable value. The introduction of new products or services, new methods of production, distribution, or marketing, or the tapping of new markets have been the traditional sources of value creation through innovations but in this case, new market was not targeted. In this case, no complementarities were present between product and services or in between technologies. Such complementarity elements add value if present. So, novelty's one attribute was not present in the case and two of complementarity value source. Absence of two main attribute of complementarity makes value generated acceptable for this case.

Case study 2:

UET and KFC collaboration case study lacks two attributes of complementarity value source and one of novelty which makes value generated acceptable.

Case study 3:

In ZONG case study, one attribute of complementarity value source is not present which was complementarity between products and services but as the case was about brand name suggestions and it doesn't involve products and services bundling so it doesn't effect value generation. So, because of all the value sources, value generated in this particular case is desirable.

\section{Discussion}

For the most part, crowdsourcing ought to be utilized when an organization is not ready to comprehend an errand all alone and when it is hard to choose a suitable temporary worker. In the utilization of crowdsourcing an organization must know about the development of its group and that the included gatherings have full access to the substance shared by means of the crowdsourcing stage. The four wellsprings of significant worth creation (secure, complementarities, productivity, and curiosity) characterized by Amit and Zott (2001) impact the era of significant worth by crowdsourcing regardless of what sort of crowdsourcing methodology is utilized. This structure was utilized to break down the wellsprings of significant worth creation for the distinctive cases which utilized crowdsourcing. The model backings organizations to see how esteem can be created utilizing crowdsourcing and what components dissects produced esteem.

\subsection{Value Risk Analysis of Crowdsourcing}

The value and risk management should not be viewed as separate activities but incorporated as an integrated part of project management. Each is reciprocal to the next in adding to venture achievement. Both hazard and esteem administration are expected to expand the odds of a venture's prosperity. The explanation behind this lies in the diverse yet reciprocal destinations of each train. It is common practice to treat value generation and risk management as separate processes but they can be integrated. Activities resulting from combining value generation activates and risk management activities are illustrated ahead.

As expounded, in crowdsourcing the group tries to connect with for a shared objective to tackle an issue or add to an item or benefit and the inspiration is restricted by time. One issue is communicating an open call to the most suitable ability pool or target swarm. Setting objectives well ahead of time and checking the accomplishments in transit has been turned out to be critical for an effective outsourcing effort in light of the fact that to the nearness of specific dangers. 
Dangers can happen whenever amid process and they should be taken care to finish action/assignment successfully while creating an incentive in result.

Risk Management:

Identified risks are categorized into five risk dimensions and risk score is calculated for each risk dimension. Turbulence risk, which pertains to the uncertainty, unpredictability and increasing complexity of the business environment, was seen by the respondents as the greatest risk of crowdsourcing. Because they are associated with unforeseen events, they could overlap with the other types of risks. When risks are studied in specific case studies, following are the results:

Table 21. Risks in case studies

\begin{tabular}{|l|l|}
\hline Case studies & Risk identified \\
\hline Case 1: Lipton talent hunt & Turbulence risk, Quality risk, Financial risk \\
\hline Case 2: UET and KFC collaboration & Turbulence risk, organizational/societal risk \\
\hline Case 3: ZONG & Turbulence risk, organizational/societal risk, low participation risk \\
\hline
\end{tabular}

All the risks (risk dimensions) are listed below with their risk scores:

Table 22. Risks and their severity

\begin{tabular}{|l|l|}
\hline Risk Dimension & Risk score \\
\hline Turbulence Risks (case study 1,2) & 15 \\
\hline Turbulence Risks (case study 3) & 20 \\
\hline Organizational and societal Risks (case study 2,3) & 4 \\
\hline Quality Risks (case study 1) & 8 \\
\hline Financial Risks (case study 1) & 8 \\
\hline Low Participation Risk (case study 3) & 2 \\
\hline
\end{tabular}

\subsection{Value Generation}

For the value generation, case studies are empirically studied and Amit \& Zott's model of value generation is adapted as it defines four value sources which are novelty, efficiency, complementarities and lock-in. Case studies are mapped over these value sources. A criterion has been proposed on which it is decided that which case is generating desirable value, which one is generating acceptable value and which one is generating undesirable value. On the basis of attributes' presence of value sources (Amit \& Zott's model) in cases, following results are derived:

Table 23. Value generated for Case studies

\begin{tabular}{|l|l|}
\hline Case studies & Value generated \\
\hline Case 1: Lipton talent hunt & Acceptable \\
\hline Case 2: UET and KFC collaboration & Acceptable \\
\hline Case 3: Zong & Desirable \\
\hline
\end{tabular}

\subsection{Value- Risk Analysis}

While carrying out the above-mentioned process in table 12, both values and risks can be managed alongside. All three cases risks and values are listed in table 14 and table 15 respectively. Below mentioned scattered plot shows the risk severity and value acceptability respective to cases. Scale for value is defined as:

- $\quad$ undesirable value $=0-3($ values from 0 to 3$)$

- $\quad$ acceptable value $=4-7$ (values from 4 to 7$)$

- desirable value $=8-10$ (value from 8 to 10 ) Scale for Risk is defined as:

- $\quad$ Risk appetite $=0-5$ (values from 0 to 5 )

- $\quad$ Risk tolerable = 6-10 (values from 6 to 10$)$

- $\quad$ Severe risk = 11 and above (all the values above 10 lies in severe risk)

The =RANDBETWEEN() Command is used to have a random number from the range of 0-3, 4-7 and 8-10 respectively. Risks values are added in Y-axis as per the risk score calculated (table 13, 14). Points on scattered plot displays date label as per format (case $\mathrm{a} / \mathrm{b} / \mathrm{c}$ ) $\mathrm{x}, \mathrm{y}$ where $\mathrm{x}$ means 'value' values on $\mathrm{x}$-axis and y represents risk value at y-axis. As 0-3 values are undesirable values, 4-7 are acceptable values and 8-10 are desirable values so the command is used to generate random numbers for respective value range. 


\subsection{Results}

Identified risks are categorized into five risk dimensions and risk score is calculated for each risk dimension. Their score varies according to their impact and likelihood of occurrence. A criterion has been set to evaluate those risks. According to the scattered plot result, case study 3 has a scattered plot shows different points which defines specific case's generated value at some risk level. =RANDBETWEEN() is used to have a value number point where its risk severity is low and value generated at that risk falls in desirable value category so the point '(case 3 ), 8,2 ' is the point in case study 3 which is generating desirable value in presence of some risk level. There is another point on scattered plot and '(case 3), 10, 4' these both point shows that in case study 3, desirable value is generated which certain risk level. And case study 3's third point i.e. '(case 3), 10, 20' it also shows desirable value generation at maximum risk. Results shows all the values generated in each case study in presence of some risk level. It shows the how much successful crowdsourcing process was for a particular case study.

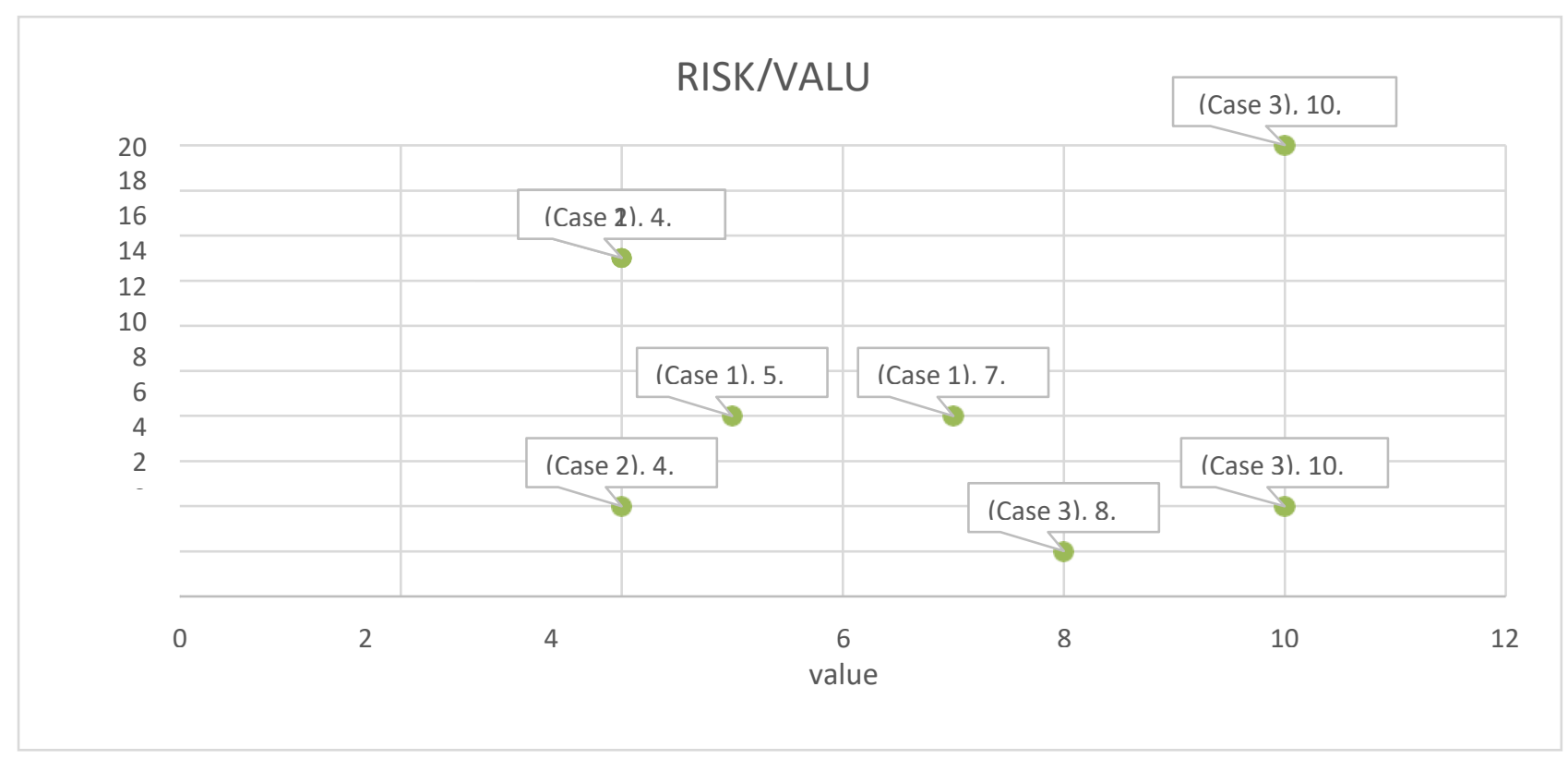

Fig.6. Value Risk Analysis-Scattered Plot

\section{Conclusion}

This section summarizes all lessons learned. This dissertation presented a methodology for crowdsourcing process in business context along with the methodology of risk management in crowdsourcing. Crowdsourcing, is normally known as "massive outsourcing" or "voluntary outsourcing", is viewed as the act of selecting a specific task and outsourcing it to a massive group of people through the Internet or via an open call. To address the central aim of the research to provide an answer for the question on 'How to manage risks of crowdsourcing' and to identify those risks that are involved with the use of crowdsourcing in a business context, risk management methodology is proposed and then applied to three case studies which were selected by visiting three well reputed organizations.

Case studies are the cases in which those organizations practiced crowdsourcing. Data is gathered by conducting openend interviews to the practitioners. Based on the varied answers of participants on the risk management processes used, it could be gleaned that though there are risks involved in crowdsourcing, they can be easily taken care of by proper management of the process. Several risk management approaches by the participants are practical in nature, though some recommendations are very creative, such as anonymizing the data and gamifying the process, reflecting participants' relatively extensive experience with crowdsourcing. Value generation of the crowdsourcing concepts by Amit \& Zatt are mapped to generate value from case studies. Risk management and value generation are integrated to do value-risk analysis. Value-risk analysis shows the values generated by the case studies in presence of certain risk factor and risk level. Results shows how much value is generated by a case study in presence of what risk factor. The scientific contribution of this research work is a better understanding of the crowdsourcing process and the risks associated with it. Managing those risks and generating value. 


\section{References}

[1] Galdon, J. L., Garrigos-Simon, F. J., \& Gil, I. (2015). Improving hotel industry processes through crowdsourcing techniques. In R. Egger, I. Gula, \& D. Walcher (Eds.), Open tourism: Open innovation, crowdsourcing and co-creation challenging the tourism industry. Berlin: Springer.

[2] Garrigos-Simon, F. J., Narangajavana, Y., \& Galdón- Salvador, J. L. (2014). Crowdsourcing as a competitive advantage for new business models. Strategies in E-business (pp. 20-37). US: Springer.

[3] Kleemann, F., Voß, G. G., \& Rieder, K. (2008). 'Un(der)paid innovators: The commercial utilization of consumer work through crowdsourcing', Science, Technology \& Innovation Studies, 4(1), 5-26.

[4] Hugh, G. (2010) SXSW: the era of crowdsourcing: guiding principles, [Online].Available at: http://hughgarry.typepad.com/hugh_garry/page/3/

[5] Raphael A., Cristoph Z. (2001). 'Value creation in e- business', strategic management journal, (June 2001)

[6] Hugo W. (2010) Towards 2011: An information technology strategy for SAEON. [pdf] [Online]. Available at: http://www.eepublishers.co.za/images/upload/SAEON_Suppl ement_2010.pdf

[7] Kannangara, S. N., and Uguccioni, P. (2013) 'Risk Management in Crowdsourcing-Based Business Ecosystems', Technology Innovation Management Review, (December 2013: Living Labs and Crowdsourcing). 7374

[8] Kittur, A. et al. (2013) 'The Future of Crowd Work', presented at the CSCW Conference on Computer Supported Cooperative Work and Social Computing, San Antonio, Texas, 2013.

[9] Andriole, S. J. (2010) 'Business impact of Web 2.0 technologies. ', Communications of the ACM, 53(12), pp. 67- 79.

[10] Casares-Giner et al. (2011) 'Mobility models for mobility management', Network performance engineering, pp. (716- 745), Springer

[11] Flinders, K. (2009), 'Crowdsourcing reveals 600 search engine flaws', [Online]. Available:http://www.computerweekly.com/Articles/2009/09/1 5/237731/crowdsourcing reveals- 600- search-engineflaws.htm

[12] Viotti, M., Bowman, C., Harris, T., Mercuri, M., and Satorius, B. (2012) 'Mars Public Engagement Program', Jet Propulsion Laboratory, 4800 Oak Grove Dr, Pasadena, CA 91109.

[13] Saxton, G. D., Onook, O. and Rajiv, K. (2013) 'Rules of crowdsourcing: Models, issues, and systems of control', Information Systems Management, 30(1), pp. 2-20.

[14] Hoover, J. (2009) 'Web 2.0 Expo: Startup aims at public policy crowdsourcing', Information Week Government, November 19 [Online]. Availableat: management/showArticle.jhtml?articleID=221900331

[15] Tapscott, D. and Williams, A. D., (2008) Wikinomics: How mass collaboration changes everything. New York: Portfolio.16. Garrigos-Simon, F.J. (2012) 'Participation throughout the importance of crowdsourcing crowd', 6th International Conference on Industrial Engineering and Industrial Management, 2012. Estellés-Arolas, E. and González-Ladrón-de-Guevara,

[16] F. (2012) 'Towards an integrated crowdsourcing definition', Journal of Information Science, 38(2), pp. 189-200.

[17] Kazai G. (2011) Lecture: In Search of Quality in crowdsourcing for Search Engine Evaluation, 33rd European conference on Advances in Information retrieval. Springer Verlag, Berlin/Heidelberg. (Lecture Notes in Computer Science 6611, pp. 165-176)

[18] Howe J. (2006a) 'The rise of crowdsourcing', Wired, pp. 1-4.

[19] Howe J. (2006b) Crowdsourcing: A definition. Crowdsourcing: Why the Power of the Crowd is Driving the Future of Business. [Online]. Available at: http://crowdsourcing.typepad.com/cs/2006/06/crowdsourcing_a.html

[20] Antikainen, M.J. and Vaataja, H.K. (2010), 'Rewarding in Open Innovation Communities-How to Motivate Members', International Journal of Entrepreneurship and Innovation Management, pp. 440-456.

[21] Howe, J. (2008) Crowdsourcing: Why the power of the crowd is driving the future of business.New York: Crown Publishing.

[22] Howe, J. (2009) 'Obama and Crowdsourcing: A Failed Relationship?', Wired Blog, April 1[Online]. Available at: http://www.wired.com/business/2009/04/obama-and-crowd/

[23] Yang, J., Adamic, L. and Ackerman M. (2008) 'Crowdsourcing and knowledge sharing: strategic user behavior on task', 9th ACM Conference on Electronic Commerce, pp. 246- 25575

[24] Vakharia, D. and Matthew, L. (2013) 'Beyond AMT: An Analysis of Crowd Work Platforms', arXiv preprint arXiv:1310.1672 (2013).

[25] Alonso, O., Rose, D. E. and Stewart, B. (2008) 'Crowdsourcing for relevance evaluation.' ACM SIGIR Forum, 42(2) pp. 9-15 [Online]. Available at: http://dl.acm.org/citation.cfm?id=1480508

[26] Alonso, O. and Lease, M. (2011) 'Crowdsourcing 101: Putting the WSDM of Crowds to Work for You', fourth ACM international conference on Web search and data mining, WSDM '11 (ACM, New York, 2011) pp.1-2.

[27] Leimeister, J. M. (2012) 'Crowdsourcing', Zeitschrift für Controlling und Management (ZFCM), 56, pp. 388-392.

[28] Gireeja, R. and Lav R. Varshney (2012) 'To crowdsource or not to crowdsourcr?', Association for the Advancement of Artificial Intelligence

[29] Boches, E. (2009) 'Ideas \& Innovation: Learnings from 130 people talking about crowdsourcing'. [Online]. Available at: http://www.mullen.com/2009/08/learnings-from- 130- people-talking-about-crowdsourcing/

[30] Whitla, P. (2009) 'Crowdsourcing and its application in marketing activities', Contemporary Management Research, pp. 15-28.

[31] Woolley, A. W., Chabris, C. F., Pentland, A., Hashmi, N., and Malone, T. W. (2010) 'Evidence for a collective intelligence factor in the performance of human groups', science, 330(6004), pp. 686-688.

[32] Herrnstein, R. J. and Murray, C. (2010) Bell curve: Intelligence and class structure in American life, Simon and Schuster. 7634. Aggarwal, I., Woolley, A. W., Chabris, C., and Malone, T. (2011) 'The relationship between collective intelligence, cognitive diversity and team learning. $V^{‘}$, in 71 st meeting of the Academy of Management, San Antonio, TX. 
[33] Robu, V. H., Halpin, H. and Shepher (2009) 'Emergence of consensus and shared vocabularies in collaborative tagging systems', ACM Transactions on the Web (TWEB) 3(4) Article 14.

[34] Buecheler T., Sieg J. H., Füchslin R. M. and Pfeifer R. (2010) 'Crowdsourcing, Open Innovation and Collective Intelligence in the Scientific Method: A Research Agenda and Operational Framework', in H. Fellerman (ed.) Artificial Life XII. Twelfth International Conference on the Synthesis and Simulation of Living Systems, Odense, Denmark, 19-23 August 2010, pp. 679686.

[35] Brabham, D. C. (2012) 'The myth of amateur crowds: A critical discourse analysis of crowdsourcing coverage', Information, Communication \& Society, 15(3), pp. 394-410.

[36] Brabham,D. C. (2013) 'The Origins of Crowdsourcing'[Online]. Available at: http://dbrabham.wordpress.com/2013/02/23/the-origins-of- crowdsourcing.

\section{Authors' Profiles}

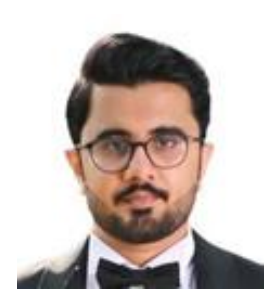

Muhammad Saady was born in Sialkot, Pakistan in 1994. He has his Master's degree in Information Technology from Virtual University Pakistan. Since 2015, he has been working in Dubai, as a Sr. Software Consultant, where he provides the IT Solutions to MENA companies. He travels across the gulf countries for software implementation, Training \& Support. Saady shares strong interests in the research and development projects of Industrial Revolution 4.0.

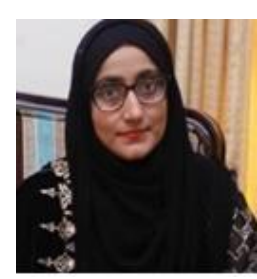

Qurat ul Ain was born in Gujrat in 1992. She did BS Software Engineering from Fatima Jinnah Women University Rawalpindi and MS in Project Management from COMSATS University Islamabad. She has done several jobs as content creator and has few research publications. Her main area of interests are Internet of things and industrial smart solutions.

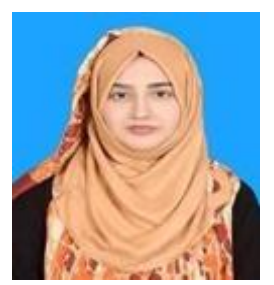

Sidra Anwar was born in Sialkot, Pakistan in 1992. She is a PhD scholar in Memorial University of Newfoundland, Canada. Previously, she has been a lecturer of Computer Science at the Govt. College Women University, Sialkot, Pakistan and member of the ORIC Steering committee since Aug 2015. She did her BS in Software Engineering from Fatima Jinnah Women University, the Mall, Rawalpindi, Pakistan and MS in Project Management from COMSATS Institute of Information Technology, Islamabad, Pakistan. She is also a Registered Engineer under Pakistan Engineering Council Act 1976. She has personally worked and supervised many projects regarding decision support systems serving multidisciplinary domains in IOT.

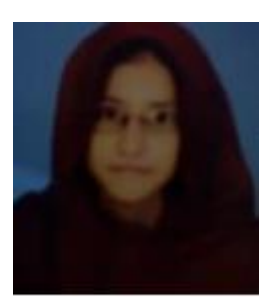

Sadia Anayat was born in Sialkot in 1998. She did her matriculation level in 2014 from, Govt. Girls Higher Secondary school Sambrial, district Sialkot in Science Subjects and her intermediate level (I.C.S) in 2016 from Superior college Sambrial, district Sialkot. Now she is doing her BS (Hons) in Computer Science (CS) from GCWU Sialkot. She is also a certified Microsoft Office specialist. Previously, she has been working in Blockchain technology and comparison between bitcoin and ethereum techniques.

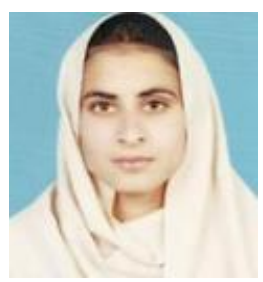

Samia Rafique was born in Sialkot, Pakistan in 1990. She has been a lecturer of Information Technology at the Govt. College Women University, Sialkot, Pakistan and member of the Quality Assurance committee since Jan 2017. She did her BS in Information Technology from Punjab University, Gujranwala Campus and her Masters in Software Engineering from International Islamic University, Islamabad, Pakistan and has her expertise in Requirement Elicitation Techniques in Different Situations of Software Development. Additionally, she has supervised numerous web-based industrial projects. 
How to cite this paper: Muhammad Saady, Qurat-ul-Ain, Sidra Anwar, Sadia Anayat, Samia Rafique, " Value-Risk Analysis of Crowdsourcing in Pakistan's Perspective", International Journal of Information Engineering and Electronic Business(IJIEEB), Vol.13, No.2, pp. 22-46, 2021. DOI: 10.5815/ijieeb.2021.02.03 